\title{
Acquisition of paired associates as a function of interpair interval
}

D. C. RIMM AND BARBARA BIGGS

ARLONA STATE UNIVERSITY

Two experiments are presented which replicated previously reported findings. Both experiments investigated the effect of varying interpair interval on acquisition of paired associates. In Experiment 1, Ss were exposed to either a 0 or 5 sec interpair interval. The group exposed to the $5 \mathrm{sec}$ interval reached the learning criterion in significantly fewer trials. In Experiment 2, Ss counted backwards over the 5 sec interval and did not learn significantly faster than a 0 interval group.

Nodine \& Nodine (1966) and Nodine, Nodine, \& Thomas (1967) have argued that in paired-associate learning, increasing the interpair interval facilitates learning by allowing for increased opportunities for rehearsal. Of the several procedural variations reported by Nodine, Nodine, and Thomas, one involved instructions to the Ss simply to "learn to associate the stimulus term with the response term." Under this condition Ss were free to rehearse a given pair over the interpair interval which was 0,2 , or $4 \mathrm{sec}$ in duration. In another condition, during the 2 or 4 sec interpair interval Ss were required to name aurally presented digits. This interpolated activity was designed to interfere with rehearsal of the pair. In terms of number of correct responses, the authors reported a highly slgnificant difference in performance between these two conditions (for 2 and 4 sec intervals), with Ss run under free rehearsal showing a marked superiority.

The present paper reports two experiments essentially replicating these results. The research, completed prior to the publication of the Nodine, Nodine, and Thomas paper, employed slightly different procedures. Nodine et al used nonsense syllables for both stimulus and response, in the present experiments stimuli were nonsense syllables but responses were single letters. In addition, in Experiment 2, a backward counting task (Peterson \& Peterson, 1959) rather than number naming was used to provide interfering interpolated activity.

\section{EXPERIMENT 1}

\section{Methed}

The $32 \mathrm{Ss}$, both males and females, were introductory psychology students at Arizona State University whose participation fulfilled a course requirement. The stimulus items were presented via an Airequipt 420 slide projector. Stimuli were CVC trigrams each having an association value of $53 \%$ (Glaze, 1928).

Subjects were required to learn which of three response alternatives (saying aloud "A," "B," or "C") was associated with each of six nonsense syllables. Stimuli were projected on the wall in front of $S$, and after each response $E$ told $S$ which response was correct. The stimulus remained on the wall for approximately $1 \mathrm{sec}$ after correction. For the Zero Delay group (16 Ss, elght males and eight females), the next stimulus was then presented Immediately. For the Five Sec Delay group (16 Ss, eight males and eight females) there was a $5 \mathrm{sec}$ interval between the removal of a given stimulus and presentation of the next. A trial consisted of the presentation of all six syllables, with order of syllables varying randomly from trial to trial. Criterion of learning was two consecutive errorless trials. Any $S$ not reaching criterion by Trial 20 was arbitrarily given a score of 20 trials.

Resulis

Mean trials to criterion for Ss in the Zero Delay and Five Sec Delay groups were, respectively, 10.44 and 6.69. This difference was significant $(t=2.39$, $\mathrm{df}=30, \mathrm{p}<.02$ ).

\section{EXPERIMENT 2}

\section{Method}

The $32 \mathrm{Ss}$, both males and females, were introductory psychology students at Arizona State University. None of them had acted as $\mathrm{Ss}$ in Experiment 1. As in Experiment 1, stimuli were CVC trigrams, each having an association value of $53 \%$ and presented via an Airequipt 420 slide projector. Materials also included a stack of $3 \times 5$ cards with three digit numbers hand printed in the center and either a "3" or a " 4 " in the lower right hand corner. The cards were placed face down on the table in front of $S$.

The procedure was identical to that employed in Experiment 1 with the following exception. For the 16 Ss (eight males and eight females) in the Five Sec Delay group, following exposure to the CVC, $\mathrm{S}$ was required to turn over the top card of the $3 \times 5$ cards, read aloud the three digit number, and count backwards from that number by elther threes or fours, according to the number in the corner. Ss were instructed to count aloud as quickly and as accurately as possible. The counting procedure, which was designed to prevent rehearsal, lasted $5 \mathrm{sec}$, terminating with the appearance of the next CVC. For the $16 \mathrm{Ss}$ (eight males and elght females) in the Zero Delay group, following exposure to the CVC, S was also required to turn over the top card and read aloud the three digit number, but was told to Ignore the " 3 " or " 4 " in the corner of the card. The next CVC was presented immediately after $S$ had read the number. As in Experiment 1, criterion of learning 
was two consecutive errorless trials, with any $S$ not reaching criterion by Trial 20 arbitrarily given a score of 20 trials.

\section{Results}

Mean trials to criterion for Ss in the Zero Delay and Five Sec Delay groups were, respectively, 14.00 and 13.19. This difference did not approach significance $(t=.42, \mathrm{df}=30, \mathrm{p}<.25)$.

\section{DISCUSSION}

The results of Experiment 1 were in accord with the finding of Nodine, Nodine, and Thomas, that increasing the interpair interval facilitates pairedassociate learning. The results of Experiment 2 lent some support to their view that such facilitation is mediated by rehearsal during the interpair interval. When a backward counting procedure was introduced so as to prevent rehearsal, performance under a $5 \mathrm{sec}$ interpair delay was not significantly superior to performance under a 0 sec delay. However, the possibility cannot be ruled out that for reasons other than rehearsal, increasing the interpair interval facilitated learning, but that counting backwards provided its own interference (Keppel, 1965) which counteracted the facilitative effect.

Within the more general context of the relationship between distribution of practice and paired-associate learning, it is rather well established (Underwood \& Ekstrand, 1967) that increasing intertrial (as opposed to interpair) interval leads to relatively little improvement in paired-associate learning. It is conceivable that failure to obtain facilitation under distributed practice results, in part, from the long lists (e.g., six to eight pairs per list) typically employed. Long lists might discourage rehearsal, even under distributed practice. Thus, the amount of information to be rehearsed on the intertrial interval might exceed S's immediate memory span, or, for long lists, rehearsal might be cumbersome, causing $S$ to "give up" trying to rehearse. If such is the case one would predict an inverse relationship between list length and improvement in learning in going from massed to distributed practice. Underwood and Ekstrand did report such a relationship; however, since item similarity was also varied, no conclusion regarding effect of list length could be drawn. If the present procedure is viewed as one involving the presentation of successive single pair "lists," the results of Experiment 1 may be interpreted as providing some support for such an inverse relationship.

References

GLAZE, J. A. The association of value of nonsense syllables. $J$. genet. Psychol., 1928, 35, 255-269.

KEPPEL, G. Problems of method in the study of short-term memory. Psychol. Bull., 1963, 63, 1-13.

NODINE, C. F., \& NODINE, B. F. Stimulus intervals, stimulus durations and difficulty level in paired-associates learning. $J$. exp. Psychol, 1966, 72, 156-158.

NODINE, C. F., NODINE, B. F., \& THOMAS, R. C. Temporal variables in paired-associates learning: The roles of repetition and number tracking during stimulus intervals. J. exp. Psychol., 1967, $73,439-445$.

PETERSON, L. R., \& PETERSON, M. J. Short term retention of individual verbal items. J. exp. Psychol., 1959, 58, 192-198.

UNDERWOOD, B. J., \& EKSTRAND, B. R. Effect of distributed practice on paired-associate learning. J. exp. Psychol,, 1967, 73 (Monogr. Suppl. Whole No. 634). 